\title{
LEGAL STANDARDS, ENFORCEMENT, AND CORRUPTION
}

Giovanni Immordino

Università di Salerno

\author{
Marco Pagano \\ Università di Napoli Federico II
}

\begin{abstract}
Stricter laws require more incisive and costlier enforcement. Because enforcement activity depends both on available tax revenue and the honesty of officials, the optimal legal standard of a benevolent government is increasing in per capita income and decreasing in officials' corruption. In contrast to the "tollbooth view" of regulation, the standard chosen by a self-interested government is a non-monotonic function of officials' corruption, and can be either lower or higher than that chosen by a benevolent regulator. International evidence on environmental regulation shows that standards correlate positively with per-capita income, and negatively with corruption, consistent with the model's predictions for benevolent governments. (JEL: D73, K42, L51)
\end{abstract}

\section{Introduction}

Designing a law cannot neglect the question of its enforcement. Stricter and more complex laws require more incisive and costlier enforcement machinery. This simple point implies that the factors that affect the deterrence of enforcement should also affect the severity of the law. ${ }^{1}$ On the one hand, a wealthier society

The editor in charge of this paper was Orazio Attanasio.

Acknowledgments: We are indebted to Alberto Bennardo, Bruno Parigi, Patrick Rey, Steven Shavell, Andrei Shleifer, Thierry Verdier, and two anonymous referees for helpful comments and suggestions. We are especially grateful to Philip Bond, who suggested fundamental improvements and showed us the way to new results in the analysis of self-interested regulators. Thanks also to Daron Acemoglu, Marios Angeletos, Marco Battaglini, Olivier Blanchard, Christophe Chamley, Tullio Jappelli, Riccardo Martina, Paolo Mauro, Ashoka Mody, and seminar participants at Bocconi, IMF, MIT, Padua, Palermo, Salerno, Siena, the 2003 conference on Institutions, Enforcement, and Corruption (Capri), the 2003 SET Conference on Organization Design, Corporate Governance and Regulation (Milan), and the 2004 European Summer Symposium in Economic Theory (Gerzensee). We acknowledge financial support from the Einaudi Institute for Economics and Finance (EIEF) and the Italian Ministry for Education, University and Research (MIUR). An earlier version of this paper was circulated under the title "Design and Enforcement of Legal Standards." Immordino is a member of CSEF; Pagano is a member of CSEF, EIEF, and CEPR.

E-mail addresses: Immordino: giimmo@tin.it; Pagano: mrpagano@tin.it

1. Starting with Becker (1968) and Stigler (1970), a large literature has investigated the optimal enforcement of laws (see Polinsky and Shavell 2000; Shavell 1993). The point that the design of laws must take into account the cost of their enforcement is forcefully made by Holmes and Sunstein (1999). 
can devote a greater amount of budgetary resources to the policing of laws, and thereby can afford more ambitious legal standards. On the other, a more corrupt bureaucracy blunts the deterrence of enforcement, and thereby requires less ambitious legal standards.

In this paper we show that these results hold if the regulator pursues the maximization of social welfare: If enforcers are corrupt, a benevolent regulator will choose less demanding legal standards than in the absence of corruption. More generally, such a regulator will respond to an increase in enforcers' corruption by lowering society's legal standards. In contrast, a self-interested regulator may respond to greater corruption either by tightening or by relaxing legal standards, depending on circumstances. This result contrasts with the "tollbooth view" of regulation proposed by Djankov et al. (2002, hereafter DLLS), which suggests that corruption should be associated with tighter regulation if regulators are self-interested. Another result that contrasts with the "tollbooth view" is that in our setting the legal standard chosen by a selfinterested regulator may be less stringent than that chosen by a benevolent one.

We make these points in the context of two alternative, but isomorphic, settings where market failures warrant intervention by a regulator. The market failures that we consider stem either from informational externalities or from real ones. As an example of informational externality, we consider an economy where product quality is unobservable, so that each seller's quality choice affects the market price. As a real externality, we study an economy where environmental quality is a public good. In both cases, in the absence of regulation producers would choose inefficiently low quality, respectively resulting in poor products or in a polluted environment. The government can remedy the problem, imposing a minimum standard and policing it by enforcement activity to detect and punish violators.

We test the predictions of the model on international data for environmental regulation, and find that regulatory standards have a positive correlation with per-capita income and a negative one with the degree of corruption, consistent with our model's predictions for the case of a benevolent regulator. Therefore our evidence does not accord with DLLS's "tollbooth view" either.

This paper is related to a vast literature that highlights the effect of corruption on regulation and enforcement. The idea that corruptibility of officials gives rise to rent-seeking by officials can already be found in Krueger (1974) and Rose-Ackerman (1978). Banerjee (1997) proves that such rent-seeking behavior is compatible with a benevolent government, in the presence of agency problems within the public sector, and Acemoglu and Verdier (2000) show that the costs entailed by this agency problem can make public intervention 
undesirable. ${ }^{2}$ The assumption that regulators may pursue a self-interested objective is present in McChesney (1987) and DLLS, who also document a positive cross-country correlation between the stringency of entry regulations and corruption. The problem of regulatory capture is analyzed also in the literature on optimal regulation under asymmetric information (Laffont and Tirole 1993).

We focus on regulation and public enforcement as remedies for market failures, but in principle one could consider more decentralized mechanisms: The enforcement of rules may be entrusted to private agents via their appeal to courts and even the design of the rules may be delegated to private agencies. These alternative mechanisms have limitations, however. One cannot rely on a plaintiff's initiative to enforce laws if documenting violations is very costly or unfeasible for individuals (as for experience goods), if the damage is socially diffuse (as for pollution), or if the perpetrator's wealth greatly exceeds that of the potential plaintiff (leading to "subversion of law"). ${ }^{3}$ Also self-regulation may lead to insufficiently stringent enforcement: DeMarzo, Fishman, and Hagerty (2005) show that a self-regulatory organization mandated to maximize the welfare of its members chooses laxer enforcement than customers would.

The paper is organized as follows. Section 2 explains that legal standards are beneficial in the presence of either informational or real externalities, and that their formal analysis is the same in the two cases. Section 3 lays out the model for the case of informational externalities, and characterizes the design and enforcement of the legal standard by a benevolent government. Section 4 examines how the standard is affected by the presence of corrupt bureaucrats. Section 5 explores how the results change when the government is self-interested. Section 6 presents the case of real externalities, in which legal standards refer to environmental regulation. In Section 7 we test the model's predictions using cross-country data about environmental regulation. Section 8 concludes.

\section{Rationale of Legal Standards}

In our model, the rationale of legal standards arises from a market failure. We analyze two cases: in the first, the market failure arises from an informational externality; in the other, from a real externality.

An informational externality arises when buyers cannot observe the quality chosen by individual sellers. Therefore, each seller's choice of production

2. While the social costs stemming from corrupt enforcers are much discussed, little empirical work documents these costs and explores the mechanism of corruption. An interesting exception is a recent paper on driving licences by Bertrand et al. (2007), showing that bureaucrats make it hard to pass the driving exam by failing individuals arbitrarily, irrespective of their skill. This red tape in turn implies that applicants often bribe bureaucrats to facilitate the process, and thereby incapable drivers often get a license.

3. For an analysis of the choice between different enforcement regimes, see Glaeser and Shleifer (2003). 
technology affects the expected quality and the price of the industry's output. But each producer, being a price taker, fails to take this into account, and chooses suboptimal quality. A real externality occurs when an agent's decision affects the payoff of others directly rather than via the information conveyed by the market mechanism. We analyze real externalities in a public-good setting, where firms' technological choices affect consumers' utility via the level of pollution. Each consumer, being small, has no incentive to penalize polluting firms by refraining to patronize them. Hence, the environment's quality will be suboptimally low.

We show that, in the presence of either type of externality, the optimal legal standard chosen by a benevolent legislator has the same characterization. In both cases, social welfare can be written (up to a constant) as

$$
W=u(s)-c(s)+y-e,
$$

where $u(s)-c(s)$ is the surplus (consumers' utility minus firms' costs) associated with legal standard $s$, and $y-e$ is the endowment net of enforcement costs. In both cases, the legal standard constrains the technological choice of firms: With informational externalities, it sets a minimum quality for the goods that they sell; with real externalities, it limits the environmental harm caused by their production process.

Because firms have the incentive to deviate from the legal standard, in both settings the standard must be assisted by appropriate enforcement, by ensuring that the following incentive constraint holds:

$$
c(s) \leq c(q)+L(q, s, l, e), \quad \forall q \neq s .
$$

Under this constraint, firms prefer to abide by the law rather than deviating to an alternative choice $q$ and paying the expected penalty $L$, which in turn depends on the actual penalty $l$ and the enforcement activity $e$. In setting these variables, the government must take into account also the feasibility constraint

$$
e \leq y-c(s)
$$

that is, the resources devoted to enforcement activity, $e$, cannot exceed the economy's per-capita endowment $y$ net of the resources used in the production of the quality good $c(s)$.

In what follows, we develop the analysis in detail for the case of the informational externality between producers and consumers of a quality good (Sections 3,4 , and 5). We then deal more briefly with the case of real externalities (Section $6)$, where legal standards refer to environmental regulation. 


\section{Quality Standards}

In this section we illustrate the basic idea in terms of the relationship between the buyer and the producer of a "quality good," namely, an object whose quality is not observed by the buyer but affects his valuation of the good. The quality of the good is chosen by the producer, and it is not observable by the government except via the costly enforcement of a minimum standard. Therefore, we have a moral hazard problem with costly monitoring between the government and the producer.

\subsection{Firms}

The quality good is produced by identical firms, uniformly distributed on the unit interval. Firms operate under constant returns to scale and compete à la Bertrand. The profit from selling a unit of the good is a function of its quality, which affects both the price that consumers are willing to pay and the production cost. ${ }^{4}$ The firms' profits are $\pi=v(q)-c(q)$, where $v(q)$ is the unit price of a good of quality $q$ and $c(q)$ is its cost. The cost function is increasing and convex in $q$, with $c(0)=0$. The market game is one-shot: we do not consider repeated sales. ${ }^{5}$

\subsection{Consumers}

The utility function of the representative consumer is defined over the consumption of two goods: a continuous and homogeneous good $x$ and the quality good. All magnitudes are measured in units of the homogeneous good (the "numéraire"). The consumer demands a single unit of the quality good and spends the rest of his disposable income on the numéraire good. His utility is

$$
U=x+u(q),
$$

where $u(q)$, the utility drawn from the quality good, is increasing and concave in $q$, with $u(0)=0$. Therefore, the demand for this good is elastic in the quality dimension but inelastic in the quantity dimension: the good's reservation price depends on $q$, whereas the quantity is fixed at 1 unit.

4. The quality measure $q$ can be seen as a summary measure of several dimensions of "quality." For instance, in the case of chicken, it could be a synthetic index of the quality of chicken feed, the preservatives added to the meat, the method used to raise chicken, and so forth. This implies that a producer can raise the quality $q$ either along a particular dimension (the "intensive margin"), or by including a previously neglected dimension (the "extensive margin" of quality). By the same token, a regulator can mandate higher standards either by imposing more stringent criteria along given dimensions (a "stricter" law) or by increasing the number of parameters considered (a more "complete" law).

5. In a context with repeated interactions, the producers' moral hazard may be tempered via reputation-building. 
The consumer's budget constraint is

$$
x+v(q) \leq y+\pi-t,
$$

where the expression on the left-hand side is the consumer's total spending, $y$ is his (positive) initial endowment, and $t$ is the net tax burden (taxes minus transfers). Taxes are assumed to be used only to pay for enforcement, so that in the absence of enforcement $t=0$.

\subsection{Unregulated Quality}

If quality is observable, the first-best allocation emerges as the competitive market equilibrium. The first best is found by maximizing expression (1) with respect to $x$ and $q$, subject to the budget constraint (2) and to the zero-profit condition

$$
\pi=v(q)-c(q)=0,
$$

because this is equivalent to maximizing social welfare

$$
\max _{q} W=y+u(q)-c(q) .
$$

As social welfare is a concave function of quality $q$, the necessary and sufficient condition for its maximization is

$$
u^{\prime}(q)=c^{\prime}(q) .
$$

The value of $q$ that solves condition (5) is the first-best (fb) level of quality $q^{f b}$. We denote the corresponding level of social welfare by $W^{f b}$.

This allocation coincides with the Nash equilibrium of an extensive-form Bertrand game, where firms choose the quality $q$ of the good they produce and a price function $v(q)$. The strategy of firm $j$ is a vector

$$
s_{j}=\left(q_{j}, v\left(q_{j}, q_{-j}\right)\right),
$$

where $q_{-j}$ is the vector of qualities chosen by competing firms. A Nash equilibrium obtains when all firms choose the first-best quality and price $\left(q^{f b}, v\left(q^{f b}\right)\right)$, because no firm can profitably deviate from it. ${ }^{6}$

6. There are three possible deviations. First, choosing a different quality $q_{j} \neq q^{f b}$ and $v_{j}=v\left(q^{f b}\right)$ is not a profitable deviation because $q_{j}>q^{f b}$ implies losses, whereas $q_{j}<q^{f b}$ implies zero demand. Second, setting a different price $v_{j} \neq v\left(q^{f b}\right)$ and $q_{j}=q^{f b}$ implies losses if $v_{j}<v\left(q^{f b}\right)$ and zero demand if $v_{j}>v\left(q^{f b}\right)$. Finally, no firm will choose to deviate by setting both a price $v_{j} \neq v\left(q^{f b}\right)$ and a quality $q_{j} \neq q^{f b}$. If all other firms offer the first-best quality and price, no consumer will accept a combination of price $v_{j} \neq v\left(q^{f b}\right)$ and quality $q_{j} \neq q^{f b}$ such that firm $j$ makes zero profits, by the very definition of a first-best allocation. A fortiori, no consumer will accept a combination of price $v_{j} \neq v\left(q^{f b}\right)$ and quality $q_{j} \neq q^{f b}$ such that firm $j$ makes positive profits. 


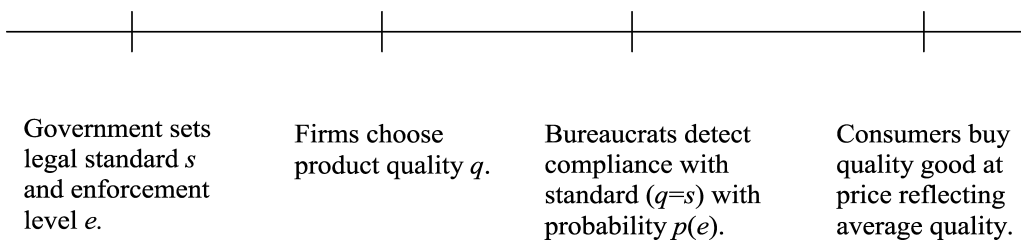

FIGURE 1. Timeline with unobservable quality.

If, instead, product quality is privately unobservable, then firms set quality at its minimum level: $q=0 .^{7}$ No positive level of quality is an equilibrium: If consumers expect this level, any firm that deviates by providing lower quality will make profits. In the next section we show that such market failure can be tempered by legal standards.

\subsection{Regulated Quality}

If the government's objective is to maximize social welfare, it can intervene to reduce the market failure described previously, by designing a law that sets a minimum quality standard $s$ and a penalty function $l(q, s)$ setting the liability of violators, and by choosing the resources $e$ assigned to enforcement. We assume that the penalty is monetary ${ }^{8}$ and cannot exceed an upper bound $\bar{l}<y-t+\pi$. This upper bound arises from limited liability, and implies that the first-best cannot be achieved. ${ }^{9}$

Figure 1 illustrates the sequence of moves. First, the government chooses the standard $s$ and the level of enforcement $e$. Then, firms choose the quality level $q$ and the corresponding price $v(q)$. Next, bureaucrats enforce the standard by inspecting firms, detecting non-compliance with probability $p(e) .{ }^{10}$ Finally, consumers buy the good at a price that reflects its average quality.

7. We assume that producers cannot offer a quality guarantee, because it is too costly for consumers to verify. For instance, it would be prohibitively expensive for a consumer to check whether a chicken in the supermarket was raised with hormones or whether it is free-range, or whether the electromagnetic waves of a portable phone exceed a safety threshold.

8. The model could accommodate a non-monetary sanction, for instance imprisonment. The social cost of imprisonment should then be accounted for in the expression for social welfare. In this case, the optimal monetary sanction is always maximal, as in our model (see the following), but the non-monetary sanction may not be set at the maximal level (Shavell 1991). However, our results concerning the relationship between standards and enforcement would be qualitatively unchanged.

9. Another motivation for the upper bound can be the danger of "subversion of justice" : too high a penalty may induce agents to invest in legal strategies to avoid punishment or in intimidating and bribing officials (Malik 1990; Glaeser and Shleifer, 2003).

10. In our setting, the government precommits to the probability of detection $p(e)$ by allotting the resources $e$ to enforcement activity. One can think of $e$ as the salaries paid to police: Once hired, each police officer detects violations with a probability determined by technological factors such as transport costs, population density, and social norms. 
The enforcement technology features decreasing marginal productivity: formally, $p^{\prime}(e)>0$ and $p^{\prime \prime}(e)<0$. The firm's expected liability is $L=p(e) l(q, s)$. Thus with government regulation, expected profits become

$$
\pi=v\left(q^{E}\right)-c(q)-L .
$$

The quality good's price $v$ depends on the quality expected by consumers, $q^{E}$, and its cost $c$ to the producer depends on the actual quality level, $q$. The variable $L$ measures also the government's revenue from penalties, $p(e)$ being the fraction of inspected firms.

Enforcement is financed by taxes and revenue from penalties: ${ }^{11}$

$$
e=t+L \text {. }
$$

Because firms earn zero profits, a benevolent government will maximize the utility of consumers, its control variables being consumption $x$, the quality standard $s$, the enforcement level $e$ and the penalty $l$ :

$$
\max _{x, s, e, l} U=x+u(s)
$$

subject to the incentive constraint

$$
v(s)-c(s)>v(s)-c(q)-L(e, q, s, l), \quad \forall q \neq s,
$$

and to the feasibility constraint ${ }^{12}$

$$
x=y-e-c(s) \geq 0,
$$

which ensures that consumption of the numéraire is non-negative. Substituting $x$ from constraint (9) into the objective function, the problem becomes the maximization of social surplus

$$
W=u(s)-c(s)+y-e,
$$

subject to the incentive constraint (8) and the feasibility constraint $x \geq 0$, as in the general formulation of the government's problem presented in Section 2.

As in Becker (1968), for any positive enforcement level it is optimal to set the penalty at the maximum feasible level: $l^{*}=\bar{l}$ if $e>0 .{ }^{13}$ As a result, the expected

11. Because utility is linear in $x$, we are assuming lump-sum taxation. However, distortionary taxes would not change our qualitative results. The main difference would be that, by making enforcement more costly, tax distortions would lower the optimal standard compared to lump-sum taxation.

12. The constraint (9) derives from the consumer's budget constraint (2) taken with equality, the government's budget constraint (7), and the definition of profits (6), together with the feasibility constraint $x \geq 0$.

13. Suppose in fact that $l<\bar{l}$. Then $l$ could be raised and $e$ lowered while keeping $L$ constant. The social surplus $u(s)-c(s)$ in the objective function would be unchanged but the enforcement cost $e$ would be lower, so that welfare $W$ would be higher, contradicting the optimality of $l$. 
penalty is $L(e, q, s, l)=p(e) \bar{l}$. To obtain the optimal enforcement level, we use the incentive constraint (8) with equality, because the optimal policy requires this constraint to be binding. If not, the government could increase welfare by lowering enforcement $e$, for any given $\bar{l}$. Next, notice that, in case of non-compliance, the firm would optimally deviate to a zero-quality level, since this would minimize its cost. ${ }^{14}$ Finally, since the detection probability $p(e)$ is monotonically increasing, it can be inverted to yield the enforcement level required to sustain the standard $s$ :

$$
\hat{e}(s)=p^{-1}(c(s) / \bar{l}) .
$$

From the properties of the production technology $c(s)$ and the detection probability $p(e)$, it is immediate that the optimal enforcement $\hat{e}$ is increasing and convex in the standard $s$ and decreasing in the maximum penalty $\bar{l} .{ }^{15}$ The positive relationship between enforcement and legal standards highlights their complementarity: A more demanding standard invites non-compliance by firms, so that it must be assisted by more intensive policing.

Using this intermediate result, the problem can be restated simply as the choice of the optimal standard $s$. Replacing the optimal enforcement (11) into the objective (10) and taking into account the feasibility constraint (9), one obtains the Lagrangian

$$
\max _{s} u(s)-c(s)+y-\hat{e}(s)+\lambda[y-\hat{e}(s)-c(s)],
$$

where $\lambda$ is the Lagrange multiplier. The first-order conditions of this problem are

$$
\begin{gathered}
u^{\prime}\left(s^{*}\right)=\left(1+\lambda^{*}\right)\left[c^{\prime}\left(s^{*}\right)+\hat{e}^{\prime}\left(s^{*}\right)\right], \\
\lambda^{*}\left[y-\hat{e}\left(s^{*}\right)-c\left(s^{*}\right)\right]=0 .
\end{gathered}
$$

The optimality condition (13) differs from the first-best condition $u^{\prime}\left(q^{f b}\right)=$ $c^{\prime}\left(q^{f b}\right)$, because its right-hand side is larger. Therefore, by the concavity of $u(\cdot)$ the following result is immediate.

Proposition 1 (Second-best Standard). The optimal quality standard $s^{*}$ is lower than the first-best quality level $q^{f b}$.

Intuitively, a benevolent government takes into account the enforcement costs of any given standard, and therefore ends up choosing a standard $s^{*}$ that is less ambitious than the first-best level. With such a standard, firms will charge the

14. As a result, $c(s)=c(0)+p(e) \bar{l}$. Recalling that $c(0)=0$, we have $c(s)=p(e) \bar{l}$.

15. The derivative of enforcement with respect to the standard is increasing: $p^{\prime-1}(c(s) / \bar{l}) c^{\prime}(s) / \bar{l}>$ 0 , and convex: $p^{\prime \prime-1}(c(s) / \bar{l})\left(c^{\prime}(s) / \bar{l}\right)^{2}+p^{\prime-1}(c(s) / \bar{l})\left(c^{\prime \prime}(s) / \bar{l}\right)>0$. The signs can be easily assessed recalling that $p(\cdot)$ is increasing and concave, and that $p^{-1}(\cdot)=1 / p^{\prime}(\cdot)$. 

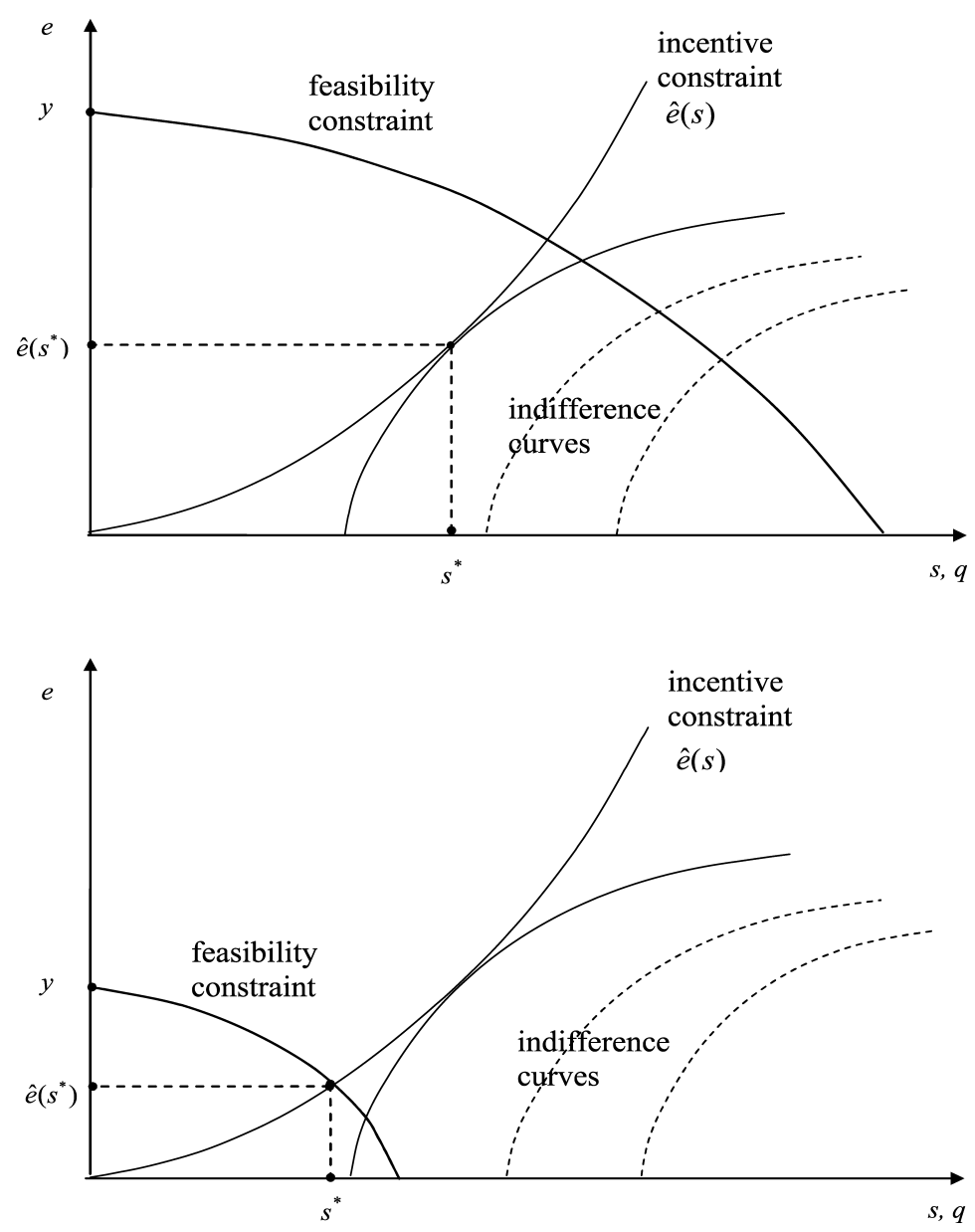

FIGURE 2. Second-best legal standard and enforcement.

competitive price $v\left(s^{*}\right)=c\left(s^{*}\right)$, and consumers will be willing to pay such a price: Because the consumer surplus $u(s)-c(s)$ is zero for $s=0$ and increasing for $s$ below the first-best level $q^{f b}$, it must be non-negative for the quality level $s^{*}$, that is, $u\left(s^{*}\right) \geq c\left(s^{*}\right)$.

Figure 2 illustrates the second-best quality level. The convex function $\hat{e}(s)$ shows the minimum enforcement required for each standard from equation (11). The function is bounded above by the feasibility constraint, which is decreasing and concave, as can be seen by differentiating constraint (9). The government's preferences are described by a field of concave, upward-sloping social indifference curves, from the properties of the welfare function $W(e, q)$ : Their slope $u^{\prime}(q)-c^{\prime}(q)$ is positive for quality levels lower than the first best $q^{f b}$, and is decreasing by the concavity of $u(q)$ and the convexity of $c(q)$. 
The figure illustrates the two possible cases that may arise. In the upper graph, the feasibility constraint is not binding $\left(\lambda^{*}=0\right)$ and the optimal values of $e$ and $s$ are at the tangency between the lowest indifference curve and the $\hat{e}(s)$ function. In the lower graph, instead, the feasibility constraint is binding $\left(\lambda^{*}>0\right)$. The second-best that corresponds to the tangency point cannot be achieved, because income $y$ is insufficient to enforce the second-best quality level. In this situation, the entire income is spent on the quality good. The resulting constrained standard corresponds to the intersection between $\hat{e}(s)$ and the feasibility constraint.

Figure 2 can be used also to investigate how the optimal quality standard $s^{*}$ responds to changes in the maximum penalty $\bar{l}$ and in income $y$. In the upper graph, where the feasibility constraint is slack, an increase in the maximum penalty $\bar{l}$ shifts the $\hat{e}(s)$ function downward (except at zero), so that the incentive constraint moves to the right in Figure 2, raising the optimal standard. An increase in the endowment $y$ leaves the equilibrium unaffected, as it shifts the feasibility constraint upwards. In contrast, in the lower graph in Figure 2, a larger $y$ increases the equilibrium quality level because it moves the intersection of the feasibility constraint with the $\hat{e}(s)$ function to the right. ${ }^{16,17}$ The other comparative statics are qualitatively identical to the case portrayed in the upper panel. These results can be summarized as follows.

COROLLARY 1 (Comparative Statics). The optimal quality standard $s^{*}$ is increasing in the maximum penalty $\bar{l}$, and is weakly increasing in the economy's endowment $y$.

Note that for some parameters the optimal quality standard $s^{*}$ can be zero: Laissez faire can be optimal. For instance, if the enforcement technology features a fixed cost and the economy is so poor that its resources are insufficient to cover this fixed enforcement cost, a benevolent government will opt for a laissez-faire policy, choosing $s^{*}=e^{*}=0$.

\section{Corrupt Enforcers}

So far we have assumed enforcement to be implemented by honest officials: Given a certain level of enforcement $e$ chosen by the government, the probability

16. In standard principal-agent theory, this result emerges directly from limited liability: Wealthier agents can be punished more harshly, and therefore prodded to exert more effort. In our setting, the mechanism is more roundabout: Greater wealth implies more tax revenue, which funds increased enforcement activity, which in turn sustains a higher standard.

17. The result that the second-best quality level is increasing in income generalizes beyond the quasi-linear utility case. For any preferences such that the marginal utility of quality is weakly increasing in income, the first-best quality level is itself increasing with income, which reinforces our result about the second-best. 
of detection is determined by a technical relationship $p(e)$. However, there may be agency problems within the bureaucracy appointed to enforce standards: When enforcers are self-interested, they will try to take advantage of their position to extract bribes from the firms that they inspect. By doing so, they blunt the deterrence of enforcement, as pointed out by Becker and Stigler (1974) and Polinsky and Shavell (2001). We show that the reduced effectiveness of enforcement due to corruptibility of officials leads to a lower standard. This parallels the finding by Acemoglu and Verdier (2000) that in the presence of corruption the government may optimally abstain from intervention.

To introduce corrupt enforcers in our setting, we assume that, upon inspecting a firm, an official can threaten to report it as failing to comply with the standard, irrespective of whether this is true or not. However, the bribe that he can demand in exchange for not reporting the firm will differ in the two cases. If the firm truly failed to comply, upon refusal to bribe the official it can expect to be punished with the penalty $l$. Therefore, $l$ is the largest bribe that an official can extract from a non-complying firm, in exchange for not being reported and punished. If instead the firm did comply, it may refuse to pay the official and hope to demonstrate its innocence in court. But doing so may entail a cost if the official's false evidence were to hold up in court, due to a judicial mistake or to collusion between judges and corrupt officials. Additional costs will arise from legal expenses. The expected value of these costs, to be denoted by $\alpha l$, where $0<\alpha<1$, is the largest sum that can be extorted from a complying firm. ${ }^{18}$

In this setting, the magnitude of $\alpha$ depends on how corrupt, unreliable, and costly the judicial system is. In a slightly more general setting where only some officials are corrupt, the magnitude of $\alpha$ depends also on the fraction of corrupt officials, as this fraction will determine the probability with which a complying firm will face extortion. In this case, $\alpha$ reflects not only the judicial system's failings but also the corruptibility of bureaucrats. For brevity, we shall refer to it as the "degree of corruption."

Because now the firm pays $\alpha l$ irrespective of compliance, it is more difficult to incentivize it for given enforcement $e$ and penalty $l$. Formally, under the new incentive constraint the firm pays the expected bribe $\alpha p(e) \bar{l}$ if it complies and $p(e) \bar{l}$ if it does not comply,

$$
v(s)-c(s)-\alpha p(e) \bar{l}>v(s)-c(q)-p(e) \bar{l}, \quad \forall q \neq s .
$$

Going through the same steps as in Section 3.4, we obtain the new optimal enforcement

$$
\tilde{e}(s)=p^{-1}(c(s) /(1-\alpha) \bar{l})
$$

18. The upper bound of $\alpha$ is 1 because if the expected loss from a trial were larger or equal to the penalty $l$, the firm would prefer to pay this penalty or the same amount to bribe an official. 
where the tilde denotes the optimal values chosen under the assumption of corrupt enforcers. As before, enforcement activity is increasing and convex in the standard $s$. Equation (16) shows that with corruption the enforcement required to police a given standard $s$ is larger than the second-best level (11): $\tilde{e}(s)>\hat{e}(s)$, because extortion by bureaucrats makes it harder to incentivize firms. Indeed, the enforcement required for a given standard $s$ is increasing in the degree of corruption, $\alpha$.

The standard chosen by the government must also ensure that consumers are willing to buy the quality good at the competitive price. In other words, one must worry that the consumers' participation constraint $u(s) \geq v(s)$ is met. Whereas in the absence of corruption this constraint always holds for the optimal quality $s^{*}$ (as discussed after Proposition 1), with corruption consumers' participation is not necessarily guaranteed: The expected bribe increases the firms' costs and thus may push the break-even price above consumers' reservation utility. To avoid market collapse, we must therefore explicitly impose the constraint

$$
u(s) \geq v(s)=c(s)+\alpha p(e) \bar{l},
$$

where the equality indicates that the competitive price $v(s)$ equals the production cost $c(s)$ plus the expected cost of extortion $\alpha p(e) \bar{l}$.

Formally, with corrupt enforcers the regulator's problem is to maximize social welfare (10) subject to the incentive constraint (16), the feasibility constraint (9), and the consumers' participation constraint (17). ${ }^{19}$ The optimal standard with corrupt enforcers, $s^{c}$, is characterized as follows.

Proposition 2 (Standard with Corrupt Enforcers). The optimal standard $s^{c}$ with corrupt enforcers is decreasing in the degree of corruption $\alpha$ and weakly increasing in per capita income $y$.

See Appendix A for the proof.

Intuitively, corruption induces a lower legal standard because it has a "deterrence-blunting effect": when enforcers are corrupt, policing a given standard requires more enforcement resources than otherwise, so that it is efficient for the regulator to choose a less ambitious standard than he would with loyal enforcers. By the same token, the higher the degree of corruption, the less ambitious the standard. A corollary of this proposition is that with corrupt enforcers

19. Because the feasibility constraint remains the same as in the setting with loyal officials, we are implicitly assuming that the bribe income collected by corrupt enforcers is available to meet the societal resource constraint. For instance, bribes can be spent on consumption of the numéraire or the quality good. 
the optimal standard is lower than the second-best level found in the previous section, namely, $s^{c}<s^{*}$. 20

\section{Self-Interested Regulator}

So far, the government has been assumed to be benevolent, that is, to maximize social welfare. However, a government may be captured by corrupt bureaucrats. In this case, it may value the bribes that can be extracted from firms, as assumed in the "tollbooth view" of regulation proposed by DLLS (2002). ${ }^{21}$ This theory assumes that regulators are self-interested, and therefore use regulation to create rents and extract them through bribes. DLLS (2002), who apply this principle to the design of entry regulation, state that "a direct implication of the tollbooth hypothesis is that corruption levels and the intensity of entry regulation are positively correlated" (p. 26).

In this section, we explore if this purported prediction of the "tollbooth view" is upheld within our model, once the government's objective function is amended so as to coincide with the expected bribes $E(b)$ collected by officialsan extreme case of self-interested behavior by the regulator. As in the previous section, bureaucrats are corrupt but now they capture the government itself, which chooses the standard $s$ and the enforcement level $e$ so as to maximize expected bribes $E(b)$. We shall denote the standard chosen by the government in this case by $s^{s i}$, where the superscript stands for "self-interested.",22

We will see that, in contrast to the "tollbooth view," the legal standard of a self-interested government is not always increasing in the degree of enforcers' corruption, and may actually be lower than that chosen by a benevolent government. Intuitively, a self-interested government must be careful not to choose too high a standard, as the latter raises the costs of producers and thereby can endanger the viability of the firms from which bribes are collected. This concern becomes more important as the degree of enforcers' corruption increases, which implies greater extortion costs for firms: To maintain firms' viability, an increase

20. In our setting we take the degree of corruption $\alpha$ as exogenous. However, the result just shown in the text survives even if the government can spend resources to mitigate corruption. In a former version of this paper, we allowed the government to spend money both on policing firms and on monitoring officials, so that the latter would not accept bribes. To this purpose, we assumed two layers of bureaucrats: low-level and corruptible bureaucrats, assigned to policing firms, and highlevel and incorruptible ones, whose only task is to monitor their subordinates. Also in that context, potential corruption requires a lower standard, because it increases the resources required to monitor lower-tier officials, just as in our context it increases the resources required to police firms.

21. Wade (1982) documents that, in Southern India, ministries received a pre-set kickback from the administration of the canal irrigation system.

22. Our self-interested regulator is like a corrupt central bureaucrat who optimizes bribe revenues. Indeed, as we shall see, precisely for this reason in some cases he will compensate the "greed" of enforcers by choosing softer standards to avoid killing the market. But here we do not compare centralized versus non-centralized corruption. On this point, we refer the reader to DeLong and Shleifer (1993), who show that corruption costs are lower with a corrupt central official. 


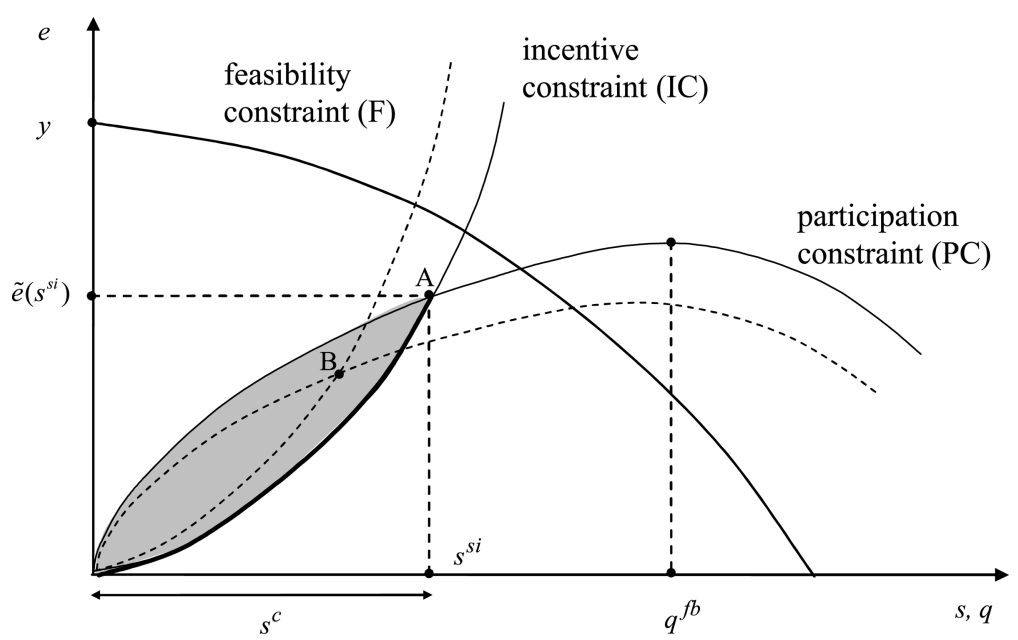

FIGURE 3. Legal standard and enforcement with a self-interested regulator (case 1).

in the degree of corruption must be compensated by lower production costs, and therefore by a lower standard.

We now proceed to show these results formally. A self-interested regulator solves

$$
\max _{x, s, e, l} E(b)=p(e) \alpha l,
$$

subject to the incentive constraint (15), the feasibility constraint (9), and the participation constraint (17). As in the previous sections, the penalty is set at its maximum level $\bar{l}$. This is because a higher penalty directly raises the expected bribe, as shown by equation (18). Therefore, the objective function can be rewritten as $p(e) \alpha \bar{l}$. To maximize it, the regulator wants to choose the largest $e$ that is consistent with the incentive compatibility, feasibility and participation constraints.

To gain some insight about the solution of the problem, we represent three possible cases in Figures 3, 4, and 5. In all three figures, the IC curve is increasing and convex in the $(s, e)$ space, and the $F$ curve is decreasing and concave, as in Figure 2. The only addition relative to that figure is the PC locus, which corresponds to constraint (17) taken with equality, and indicates combinations of $s$ and $e$ where consumers are indifferent between buying and not buying the good. This locus is increasing up to the first-best standard $q^{f b}$, and then decreasing, as can be shown by differentiating equation (17) implicitly. ${ }^{23}$ Intuitively, when the

23. This yields $d e / d s=\left[u^{\prime}(s)-c^{\prime}(s)\right] / \alpha \bar{l} p^{\prime}(e)$. When the first-best condition $u^{\prime}(s)=c^{\prime}(s)$ is met, this derivative is zero and the second derivative is negative. 


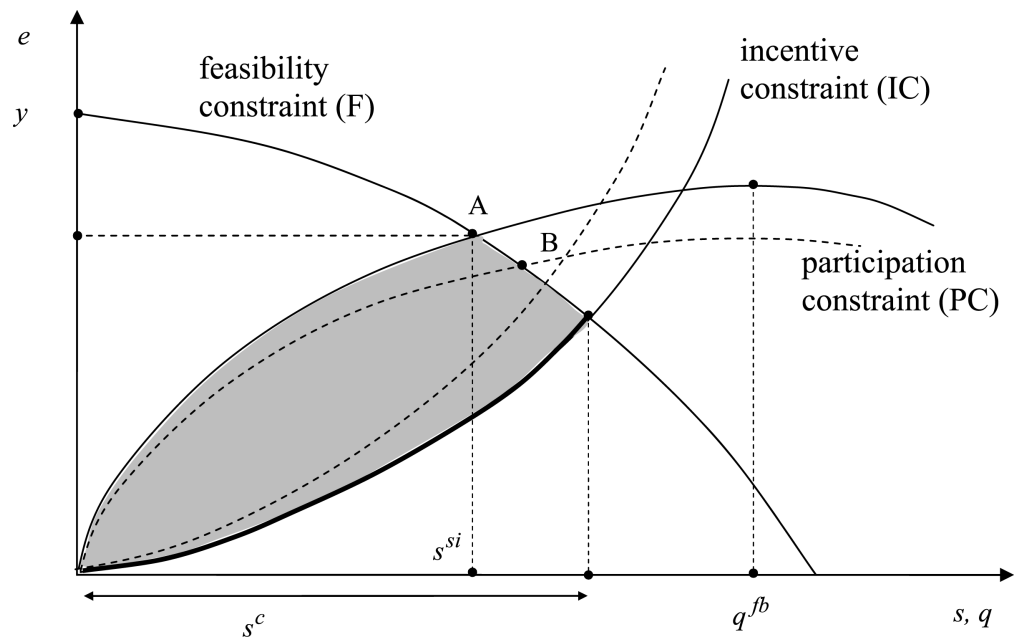

FIGURE 4. Legal standard and enforcement with a self-interested regulator (case 2).

standard is below the first best, raising it allows firms to raise prices, generating a surplus that can be appropriated by corrupt enforcers via greater extortion (higher $e$ ). Beyond the first best, further increases in the standard reduce the surplus produced by firms, so that corrupt enforcers must correspondingly reduce extortion (lower $e$ ).

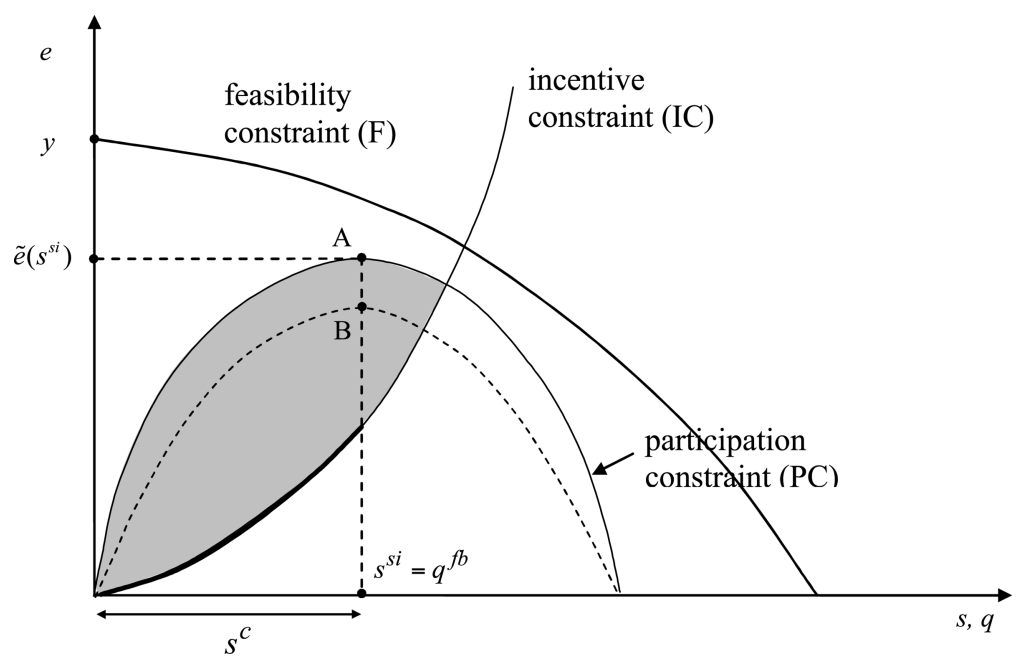

FIGURE 5. Legal standard and enforcement with a self-interested regulator (case 3). 
Points in the lens between the IC and the PC curve satisfy both the incentive compatibility and the participation constraint. Because the feasible points are those that lie below the F curve, all three constraints are satisfied in the shaded area. The optimal point-denoted by $\mathrm{A}$-corresponds to the highest value of $e$ in the shaded area, and the optimal legal standard $s^{s i}$ is the abscissa of point A. This is the intersection between the IC and PC curves if the latter occurs inside the F constraint, as in Figure 3. Otherwise, the highest feasible $e$ corresponds to the intersection between the F and PC constraints, as in Figure 4, where the IC constraint is slack.

Graphical analysis allows us to compare the optimal standard chosen by a self-interested regulator with that chosen by a benevolent one. In Figures 3, 4, and 5 , the solution that would be chosen by a benevolent regulator, $s^{c}$, lies on the thick portion of the IC curve, at a point determined by the tangency with the highest indifference curve (not drawn), unless the $\mathrm{F}$ constraint is binding, in which case $s^{c}$ is at the intersection between the IC and $\mathrm{F}$ constraint. Therefore, the legal standard $s^{s i}$ is weakly larger than $s^{c}$ in Figures 3 and 5, whereas it can be either larger or smaller than $s^{c}$ in Figure 4. In other words, there are cases in which a self-interested regulator may choose a lower legal standard than a benevolent one.

How does the optimal standard $s^{s i}$ react to an increase in corruption $\alpha$ ? As shown by implicit differentiation of constraints (17) and (16), an increase in $\alpha$ flattens the rising portion of the PC locus and steepens the IC locus, as shown by the dashed lines in the three figures. In Figure 3, the intersection between these two loci moves down and to the left-from A to B. In other words, if the F constraint is not binding, an increase in corruption reduces the legal standard $s^{s i}$ chosen by the self-interested regulator, in contrast with the prediction of the "tollbooth view." Intuitively, when $\alpha$ increases, larger extortion by enforcers lowers firms' incentives to abide by the law, which calls for a softer legal standard.

The opposite occurs in Figure 4: Here the shift of the PC locus leads to a higher standard $s^{s i}$. Intuitively, to meet the increased extortion costs firms must raise the price of their goods, which in turn requires a tighter standard. In this case, a tighter standard does not require greater enforcement because the incentive compatibility constraint is not binding.

Although in Figures 3 and 4 the IC curve intersects the increasing portion of the PC curve, the intersection may occur in the decreasing portion of the latter. The latter case is shown in Figure 5, where the highest enforcement is achieved at the maximum of the PC locus (point A), which corresponds to the first best $q^{f b}$. (Recall, however, that with corrupt enforcers the first best does not maximize welfare.) The effect of an increase in the degree of corruption $\alpha$ is again represented as the shift from point $\mathrm{A}$ to point $\mathrm{B}$ : The figure shows that the standard is set at the first-best level, and is invariant to the level of corruption. This discussion is summarized and formally proved in the following lemma. 
LEMMA 1. If the regulator is self-interested, the optimal standard $s^{s i}$ is increasing or decreasing in the degree of corruption $\alpha$, depending on whether the feasibility or the incentive constraint binds. It is invariant to $\alpha$ if neither constraint binds.

See Appendix A for the proof.

Considering that the feasibility constraint is binding for low values of the endowment $y$, this lemma predicts that in relatively poor countries the standard $s^{s i}$ chosen by a self-interested regulator should be increasing in the degree of corruption $\alpha$, in conformity to the "tollbooth view," whereas this should not be the case in relatively rich ones. Building on this lemma, the relationship between the optimal standard $s^{s i}$ and the degree of corruption $\alpha$ can be fully characterized.

Proposition 3 (Standard with Self-Interested Regulator). The relationship between the standard chosen by a self-interested regulator and corruption, $s^{s i}(\alpha)$, is an inverted $U$-shaped curve, which has either a unique maximum $\hat{s}=s^{s i}(\hat{\alpha})$ or multiple maxima equal to $q^{f b}$ over an interval $\left[\alpha_{1}, \alpha_{2}\right]$.

See Appendix A for the proof.

Intuitively, when corruption is low so that bribes are moderate, firms can bear the cost of meeting the legal standard and paying the implied bribes (the incentive constraint being slack). In this region, more corruption is associated with tighter standards, so that the "tollbooth view" applies. Conversely, when corruption is rampant, firms are so oppressed by bribes that further increases in the greed of enforcers must be balanced by more lenient standards (the incentive constraint being binding). In this region, the "tollbooth view" does not apply, because even for a self-interested regulator the main concern is to avoid "killing the market."

\section{Environmental Standards}

The analysis presented so far applies also to environmental standards. The need to impose an environmental standard arises from a public-good problem, which on surface might seem completely different from the informational asymmetry that requires product quality standards. However, the two problems are much more similar than they appear, to the point that the decision problem for the government in the two settings is the same. In both cases, government intervention is required to correct an externality in producers' decisions, as explained in Section 2.

Suppose, as before, that consumers care about two goods-a continuous numéraire good and a lumpy good—and demand a single unit of the lumpy good 
and an amount $x$ of the numéraire. The production of the lumpy good affects the quality of the environment: The more polluting is production, the lower is its unit cost. As before, $c(q)$ is increasing in $q$, this time reinterpreted as the "environmental friendliness" of the technology. Therefore, $c(0)$ is the minimum production cost, corresponding to the most environmentally harmful technology. Per-unit profits are defined as

$$
\pi=v(\bar{q})-c(q),
$$

where $v$ is the market price, to be determined by Bertrand competition.

In this reworking of the model, the value that the consumer places upon the quality good is an increasing function of the quality of the environment, $\bar{q}$, which is the average level chosen in the economy: $\bar{q}=\int_{0}^{1} q d z$. For concreteness, imagine that the quality good is a vacation in a natural resort, where each hotel pollutes the environment to a different degree depending on the technology it chooses to process its waste. If the hotels' choices result in a better environmental quality $\bar{q}$, consumers will draw greater satisfaction from a vacation. Accordingly, the utility of consumers can be rewritten as

$$
U=x+u(\bar{q}),
$$

where $u(\bar{q})$ is the reservation value of the vacation for a given environmental quality $\bar{q}$. For each consumer, the pollution level chosen by the producer that he patronizes has a negligible effect on environmental quality $\bar{q}$. Due to this externality, environmental quality is a public good.

In this setting, without government intervention Bertrand competition leads to the lowest environmental quality. The market price is bid down to the cost corresponding to the cheapest and most polluting technology, namely, $v=c(0)$. This inefficiency can be remedied by setting a minimum environmental standard $s$, so that $\bar{q}=s$.

Firms will recover the implied increase in production costs by raising the price of the lumpy good, and under perfect competition the whole increase will be passed on to consumers through price. As in Section 3.4, a benevolent government maximizes the utility of consumers over consumption $x$, the environmental standard $s$, the enforcement level $e$ and the penalty $l$,

$$
\max _{x, s, e, l} \quad U=x+u(s),
$$

subject to the incentive constraint (8) and the feasibility constraint (9). In the presence of corrupt enforcers, the regulator will also have to take into account the consumers' participation constraint (17).

This implies that the results reached in the previous sections also apply to the design and enforcement of environmental standards. If these standards are chosen 
optimally, their strictness should be positively related to the resources devoted to their enforcement, and they should be higher in wealthier countries than in poorer ones. This is reminiscent of the provisions of the Kyoto Protocol, according to which developed countries ought to bear the entire financial burden of reducing greenhouse gas emissions, while developing countries are not bound to reduce future emissions, at least not immediately.

The results on corruption also carry over to environmental regulation. If governments are benevolent, environmental standards and their enforcement should be less stringent the greater the degree of corruption. If governments are selfinterested, instead, the effect of corruption on environmental standards is predicted to be non-monotonic, that is, first increasing and then decreasing. In the following section we test these predictions using international data on environmental regulation and enforcement and the degree of corruption.

\section{International Evidence}

Our evidence concerns environmental standards, as measured by the two indicators proposed by Porter, Sachs, and Schwab (2001): (i) the "Environmental Governance" indicator, which is the principal component of responses to several survey questions, touching on regulation and enforcement, and (ii) the "Compliance with Environmental Agreements," based on survey responses. Data for these indicators are drawn from World Economic Forum (2002), hereafter WEF, and are available for 70 countries. We merge these variables with a measure of corruption drawn from the Transparency International database and a number of controls (education, religion, political, and geographical variables) to be used as instruments for corruption. Detailed definitions and data sources are given in Appendix B.

A prediction of the model is that the strictness of regulatory standards is positively related with per capita income, irrespective of the presence of corruption or the preferences of the regulator. This is consistent with the data: Figure 6 suggests that the relationship between Environmental Legislation and the logarithm of Income is positive and linear, measuring regulatory standards via the variable Environmental Governance drawn from WEF (2002).

The data also allow us to explore the relationship between legal standards and corruption. In Figure 7, environmental standards appear to be negatively correlated with corruption.

To check the robustness of the simple correlations revealed by these figures, Table 1 reports estimates obtained by regressing environmental standards on the logarithm of Income and Corruption. In the OLS regressions reported in columns (1) and (3), the coefficient of the logarithm of Income is positive, that of Corruption is negative, and both are significantly different from zero at standard confidence levels. The size and significance of the coefficient of Corruption is not affected 


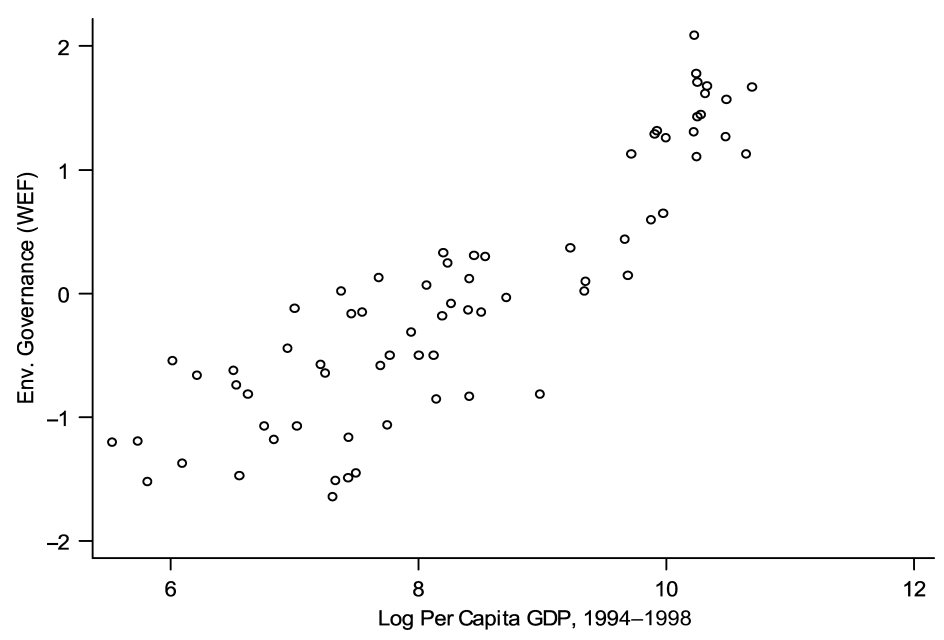

FIGURE 6. Environmental Governance (WEF data) and log per capita GDP.

by other control variables such as schooling, and there is no evidence of a nonmonotonic effect of Corruption, the coefficient of a quadratic term not being significantly different from zero. These robustness checks are not reported for brevity. Therefore, OLS estimates confirm the evidence of the bivariate plots. ${ }^{24}$

However, these estimates may be affected by endogeneity problems, in keeping with the model, where both legal standards and bribes are endogenous variables. Hausman tests reject the null hypothesis of OLS consistency in the regression reported in column (1). Therefore we re-estimate the regressions using Schooling, Civil Rights, Latitude, and Religion dummies as instrumental variables (IV). In all the IV regressions, the estimated coefficient of Income, though positive, is no longer significantly different from zero. The coefficient of Corruption remains negative and significantly different from zero.

All these correlations are consistent with our model, under the assumption of a benevolent regulator. ${ }^{25}$ Instead, it is not consistent with the model's prediction for the case of a self-interested regulator, where over some range the correlation

24. We have obtained similar results on a negative correlation between corruption and the strictness of environmental regulation by using another cross-country data set, which covers a small set of countries but provides accurate survey-based measures of the strictness of regulation. These measures are constructed from environmental reports presented to the United Nations Conference on Environment and Development (UNCED) in 1992. The data refer to 32 randomly selected countries of the 145 for which UNCED reports were presented.

25. Admittedly our estimates are also consistent with other interpretations. For instance, the positive correlation between environmental standards and per capita income may mean that environmental protection is a luxury good-the so-called "environmental Kuznets curve" discussed by Dasgupta et al. (2002). And the negative correlation between environmental standards and corruption could arise from producers' lobbying for lower environmental compliance costs, insofar as they can appropriate these cost savings in the form of extra profits. In terms of our model, this would require firms to have some market power. 


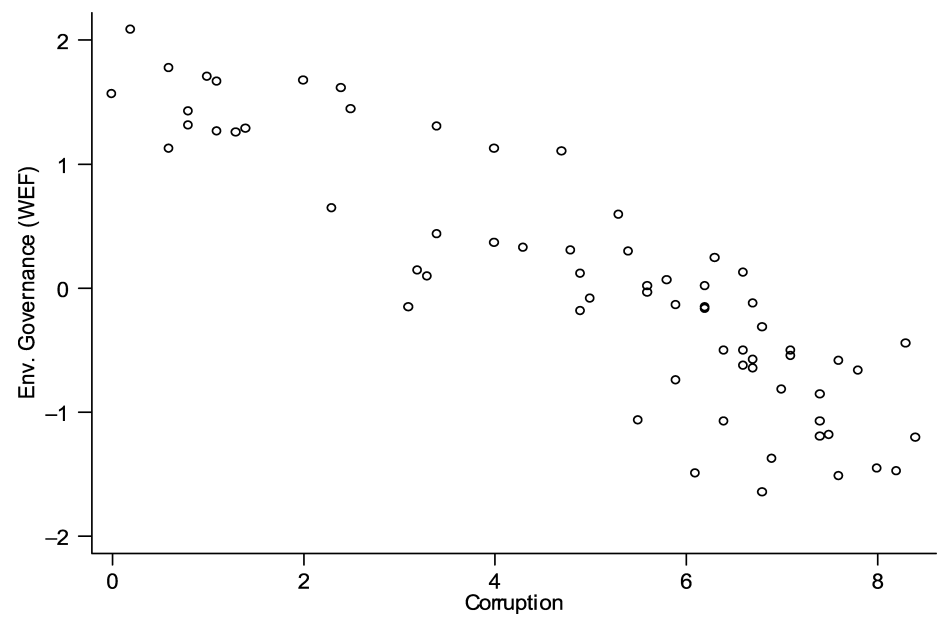

Figure 7. Environmental Governance (WEF data) and Corruption.

between corruption and legal standards should be positive. By the same token, the evidence contrasts with the prediction that DLLS (2002) associate with the tollbooth view.

It may appear puzzling that the empirical correlation between environmental regulation and corruption is opposite to that documented by DLLS for the regulation of entry, as measured by the number of procedures required for a start-up company to obtain legal status. This difference may stem from two characteristics of environmental regulation. First, in this area international treaties make it more difficult for self-interested regulators to misbehave, so that regulation may be more inspired to the pursuit of social welfare than in other areas. Second,

TABLE 1. Regression results.

\begin{tabular}{lcccc}
\hline Regression & $(1)$ & $(2)$ & $(3)$ & $(4)$ \\
Estimation Method & OLS & IV & OLS & IV \\
\hline Constant & $-1.44^{*}$ & 0.42 & -0.27 & -0.52 \\
& $(0.75)$ & $(1.40)$ & $(1.02)$ & $(1.72)$ \\
Log per-capita GDP & $0.30^{* * *}$ & 0.14 & $0.17^{*}$ & 0.20 \\
& $(0.07)$ & $(0.12)$ & $(0.09)$ & $(0.15)$ \\
Corruption & $-0.21^{* * *}$ & $-0.33^{* * *}$ & $-0.27^{* * *}$ & $-0.30^{* * *}$ \\
& $(0.04)$ & $(0.07)$ & $(0.05)$ & $(0.09)$ \\
Adjusted $R^{2}$ & 0.837 & 0.819 & 0.729 & 0.780 \\
Number of observations & 66 & 49 & 56 & 46 \\
\hline
\end{tabular}

The dependent variable is Environmental Governance (WEF data) in regressions 1 and 2, and Compliance with Environmental Agreements (WEF data) in regressions 3 and 4. Regressions 1 and 3 are estimated with ordinary least squares. Regressions 2 and 4 are estimated with instrumental variables. The instruments are Schooling, Civil Rights, Latitude, and Religion dummies. The Hausman test does not reject the hypothesis that OLS estimates are consistent in regression 3, but rejects it at the $5 \%$ level in regression 1 . Standard errors are reported in parentheses.

${ }^{*}$ Significant at $10 \% ;{ }^{* *}$ Significant at $5 \% ;{ }^{* * *}$ Significant at $1 \%$. 
environmental regulation, being relatively new, may be less affected than entry regulation by deep-seated features of legal systems-such as formalism-that may have fostered corruption. Indeed, especially in developing countries, much regulation inherited from the past is due to legal transplant by colonizers or to mechanical imitation of foreign models by national regulators. In other words, the globalized nature of environmental regulation and its relative novelty can explain why it is closer to the optimal pattern, whereas in other fields of regulation corrupt countries appear to impose tighter or more formalistic regulation. ${ }^{26}$

\section{Conclusion}

Entitling people to rights entails the budgetary costs of enforcing such rights (Holmes and Sunstein, 1999). This implies that regulators must trade the benefit of a stricter legal standard off against the cost of its enforcement. As a result, legal standards and enforcement are complements. Because enforcement activity depends both on available tax revenue and on the honesty of enforcers, the optimal legal standard is increasing in per capita income and decreasing in officials' corruption. These results hold if the regulator maximizes social welfare.

In contrast, a self-interested regulator may respond to greater corruption either by tightening or by relaxing legal standards, depending on per capita income and the degree of corruption. In particular, we show that the legal standard chosen by a self-interested regulator is first increasing and then decreasing in the degree of corruption.

The intuitive rationale for the non-monotonic relationship between legal standard and corruption is that, when corruption is low, firms can bear the cost of meeting the legal standard and paying the implied bribes. In this region, more corruption will be associated with tighter standards, as predicted by the "tollbooth view" of regulation. When instead corruption is rampant, firms are so oppressed by bribes that further increases in the greed of enforcers must be balanced by more lenient standards, because even a self-interested regulator is concerned about "killing the market." The latter result contrasts with the "tollbooth view" of regulation.

Our framework can be used to analyze different regulations. We apply it to product quality standards (when consumers cannot observe quality) and to environmental standards (when consumers do not internalize the cost of pollution).

International evidence on environmental regulation shows that standards correlate positively with per capita income, and negatively with corruption. This

26. See, for instance, Djankov et al. (2003) for procedural formalism or Botero et al. (2004) for the regulation of labor. 
result is consistent with the model's predictions for benevolent governments, and contrasts with previous evidence documenting that in other areas of regulation the stringency of rules correlates positively with corruption. This difference in results may reflect the effect of international treaties, which make it harder for self-interested regulators to misbehave in the area of environmental regulation. It may also reflect the more recent nature of this body of regulation, which may be less affected by mechanical imitation of foreign norms.

\section{Appendix A: Proofs}

Proof of Proposition 2. The problem is to maximize $u(s)-c(s)+y-\tilde{e}(s ; \alpha)$ subject to the incentive constraint (16), the participation constraint (17), and the feasibility constraint (9). Upon replacing $\tilde{e}(s ; \alpha)$ from constraint (16), the participation and feasibility constraints become

$$
u(s) \geq c(s) /(1-\alpha)
$$

and

$$
y \geq \tilde{e}(s ; \alpha)+c(s) .
$$

To show that the claim that the optimal standard $s^{c}$ is decreasing in the degree of corruption $\alpha$, consider two values $\alpha_{1}$ and $\alpha_{2}$, such that $\alpha_{2}>\alpha_{1}$, and suppose that, contrary to the claimed result, the corresponding values of $s^{c}$ are $s_{2} \geq s_{1}>0$. The proof proceeds in two steps: First, we show that under these assumptions both previous constraints are slack, so that $s^{c}$ is determined by the first-order condition; second, that this condition implies $s_{2}<s_{1}$ and thus a contradiction.

First, to show that the constraint (A.1) is slack, we note that

$$
u\left(s_{2}\right)-c\left(s_{2}\right) /\left(1-\alpha_{1}\right)>u\left(s_{2}\right)-c\left(s_{2}\right) /\left(1-\alpha_{2}\right) \geq 0 .
$$

The function $u(s)-c(s) /(1-\alpha)$ is first increasing and then decreasing in $s$, and it equals zero for $s=0$ (no intervention) and for a value $s>0$ (intervention). As we focus on $s>0$, that is, on the positive root of the equation, we have $u^{\prime}(s)-c^{\prime}(s) /(1-\alpha)<0$. This together with equation (A.3) implies that

$u\left(s_{1}\right)-c\left(s_{1}\right) /\left(1-\alpha_{1}\right) \geq u\left(s_{2}\right)-c\left(s_{2}\right) /\left(1-\alpha_{1}\right)>u\left(s_{2}\right)-c\left(s_{2}\right) /\left(1-\alpha_{2}\right) \geq 0$.

Next, to show that the constraint (A.1) is also slack, recall that $c(s)$ is increasing in $s$ and $\tilde{e}(s ; \alpha)$ is increasing in $s$ and in $\alpha$, so that

$$
y \geq \tilde{e}\left(s_{2} ; \alpha_{2}\right)+c\left(s_{2}\right)>\tilde{e}\left(s_{1} ; \alpha_{1}\right)+c\left(s_{1}\right) .
$$


Therefore, $s_{1}$ is determined by the interior optimum

$$
u^{\prime}\left(s_{1}\right)-c^{\prime}\left(s_{1}\right)-\tilde{e}^{\prime}\left(s_{1} ; \alpha_{1}\right)=0 .
$$

Because $\tilde{e}\left(s_{1} ; \alpha_{1}\right)$ is convex in $s$, it follows that

$$
\begin{aligned}
u^{\prime}\left(s_{2}\right)-c^{\prime}\left(s_{2}\right)-\tilde{e}^{\prime}\left(s_{2} ; \alpha_{2}\right) \\
\leq u^{\prime}\left(s_{1}\right)-c^{\prime}\left(s_{1}\right)-\tilde{e}^{\prime}\left(s_{1} ; \alpha_{2}\right)<u^{\prime}\left(s_{1}\right)-c^{\prime}\left(s_{1}\right)-\tilde{e}^{\prime}\left(s_{1} ; \alpha_{1}\right)=0,
\end{aligned}
$$

implying that the regulator would improve welfare by adopting a lower standard than $s_{2}$ at the corruption level $\alpha_{2}$. (The previous arguments imply that constraints (A.2) and (A.1) are still satisfied when $s$ is lowered.) The contradiction completes the proof of the claim that a larger $\alpha$ is associated with a lower $s^{c}$.

Next, to show the claim that the optimal standard $s^{c}$ is weakly increasing in the income level $y$, note that if the constraint (A.2) is slack, the $s^{c}$ is determined by the first-order condition and is unaffected by $y$. If instead the constraint (A.2) is binding, it is immediate that a larger $y$ requires an increase in $s^{c}$.

Proof of Lemma 1. As stated in the text, in this regime the regulator wants to choose the largest $e$ consistent with the incentive compatibility, feasibility, and participation constraints. Note first that the constraint (A.1) must bind: Otherwise, the regulator could reduce $s$ to slacken the incentive compatibility constraint (16) and the participation constraint (A.2), and thereby increase $e$. Moreover, generically at most two of the three constraints can bind. So there are three possibilities:

(i) If the constraint (A.2) binds, $s$ is increasing in $\alpha$;

(ii) if constraint (16) binds, $s$ is decreasing in $\alpha$; and

(iii) if neither constraint (A.2) nor constraint (16) binds, $s$ is independent of $\alpha$.

In case (i), which corresponds to Figure 4, the optimal standard solves the two equations $y-c\left(s^{s i}\right)=e(\mathrm{~F})$ and $u\left(s^{s i}\right)-c\left(s^{s i}\right)=\alpha p(e) \bar{l}$ (PC). Upon substituting $(\mathrm{F})$ in $(\mathrm{PC})$ and differentiating, we obtain

$$
\frac{d s^{s i}}{d \alpha}=\frac{p\left(y-c\left(s^{s i}\right)\right) \bar{l}}{u^{\prime}\left(s^{s i}\right)-c^{\prime}\left(s^{s i}\right)+\alpha c^{\prime}\left(s^{s i}\right) p^{\prime}\left(y-c\left(s^{s i}\right)\right) \bar{l}} .
$$

The numerator of this derivative is positive, as the probability $p\left(y-c\left(s^{s i}\right)\right)$ is greater than 0 . The denominator is also positive, because $u^{\prime}\left(s^{s i}\right)-c^{\prime}\left(s^{s i}\right)>0$ for $s^{s i}<q^{f b}{ }^{27}$ Hence, the derivative is positive. In case (ii), which corresponds to

27. Suppose in fact that $s^{s i}>q^{f b}$. Because $y-c\left(s^{s i}\right)>y-c\left(q^{f b}\right)$ and $u\left(q^{s i}\right)-c\left(q^{s i}\right)>$ $u\left(q^{f b}\right)-c\left(q^{f b}\right)$, the (F) and (PC) equations imply that the value of $e$ corresponding to $q^{s i}$ exceeds that corresponding to $q^{f b}$. Because by lowering $s^{s i}$ the government can increase $e$ and still satisfy both (F) and (PC), it follows that the optimal standard $s^{s i}$ must be lower than $q^{f b}$. 
Figure 3, the optimal standard solves the two equations $(1-\alpha) p(e) \bar{l}-c\left(s^{s i}\right)=0$ (IC) and $u\left(s^{s i}\right)-c\left(s^{s i}\right)-\alpha p(e) \bar{l}=0$ (PC). To show that $s^{s i}$ is decreasing in $\alpha$, we differentiate constraint (A.1) and obtain

$$
\frac{d s^{s i}}{d \alpha}=\frac{c\left(s^{s i}\right) /(1-\alpha)^{2}}{u^{\prime}\left(s^{s i}\right)-c^{\prime}\left(s^{s i}\right) /(1-\alpha)},
$$

which is negative because the numerator is positive and the denominator is negative by the argument offered after inequality (A.3) in the proof of Proposition 2. In case (iii), which corresponds to Figure 5, the optimal standard must only satisfy the equation $u\left(s^{s i}\right)-c\left(s^{s i}\right)=\alpha p(e) \bar{l}(\mathrm{PC})$. In this case, for any $\alpha$ maximizing $e$ is tantamount to maximizing $u\left(s^{s i}\right)-c\left(s^{s i}\right)$, which requires $s^{s i}=q^{f b}$. Hence, $s^{s i}$ is invariant to $\alpha$.

Proof of Proposition 3. For brevity, in what follows we will refer to the incentive constraint (16) as IC, the participation constraint (17) as PC, and the feasibility constraint (9) as F. Note that in the space $(s, e)$ shown in Figures 3, 4, and 5, the IC curve is increasing in $\alpha$, the PC curve is decreasing in $\alpha$, and the $\mathrm{F}$ curve is independent of $\alpha$. Two possible cases can arise.

Case 1. There exists a value of $\alpha$ such that F, PC, and IC are simultaneously binding: Graphically all three loci intersect for a triple $(\hat{s}, \hat{e}, \hat{\alpha})$ and the intersection occurs in the increasing portion of the PC curve or at its maximum $q^{f b}$ (otherwise the regulator would want to decrease $s$ and increase $e$, while still respecting IC and F). This intersection is unique because IC is increasing and convex, PC is increasing and concave, and F is decreasing. For $\alpha>\hat{\alpha}, \mathrm{PC}$ and IC remain binding (while $\mathrm{F}$ becomes slack), so that a higher $\alpha$ is associated with a lower $s^{s i}$, as shown in Lemma 1 and illustrated in Figure 3. For $\alpha<\hat{\alpha}$, F and PC remain binding (while IC becomes slack), so that a higher $\alpha$ is associated with a lower $s^{s i}$, as shown in Lemma 1 and illustrated in Figure 4. Hence, $s^{s i}$ achieves a maximum at $\hat{s}$ for $\alpha=\hat{\alpha}$.

Case 2. There exists no value of $\alpha$ such that F, PC, and IC are simultaneously binding: Graphically, there is no point where F, PC, and IC all intersect in the increasing portion of PC. In this case, there exist $\alpha_{1}$ and $\alpha_{2}>\alpha_{1}$ such that the optimal standard $s^{s i}$ is increasing in $\alpha$ up to $q^{f b}$ for $\alpha \in\left(0, \alpha_{1}\right)$, constant at $q^{f b}$ for $\alpha \in\left[\alpha_{1}, \alpha_{2}\right]$, and decreasing in $\alpha$ for $\alpha \in\left(\alpha_{2}, 1\right)$. To show this, one must distinguish three sub-cases.

Case $2 a$. PC is binding, while F and IC are not. Graphically, this occurs if the IC curve intersects the PC curve in its decreasing portion, while F is slack (as in Figure 5). In this case, the optimal standard $s^{s i}$ corresponds to the maximum of the PC curve, $q^{f b}$, where $e$ is maximal. As $\alpha$ decreases, shifting the PC curve upwards and the IC curve downwards, we get to the point where F intersects PC 
at its maximum $q^{f b}$. We denote the corresponding value of $\alpha$ by $\alpha_{1}=\left[u\left(q^{f b}\right)-\right.$ $\left.c\left(q^{f b}\right)\right] / p\left(y-c\left(q^{f b}\right)\right) \bar{l}>0$. Conversely, as $\alpha$ increases, the intersection between these ultimately occurs at the maximum $q^{f b}$. We denote the corresponding value of $\alpha$ by $\alpha_{2}=\left[u\left(q^{f b}\right)-c\left(q^{f b}\right)\right] / u\left(q^{f b}\right)<1$. For all values of $\alpha$ between $\alpha_{1}$ and $\alpha_{2}$, only PC is binding, so that $s^{s i}$ is constant at $q^{f b}$, as shown in Lemma 1 and illustrated in Figure 5.

Case 2b. For $\alpha<\alpha_{1} \mathrm{~F}$ and PC are binding, while IC is not. Graphically, this must occur at a point where the $F$ curve intersects the PC curve in its increasing portion, as in Figure 4 (otherwise it would be possible to decrease $s$ and increase $e$, while still respecting $\mathrm{IC}$ and $\mathrm{F}$ ). In this case, the optimal standard $s^{s i}$ corresponds to the intersection of the F and PC curves. Hence, for $\alpha<\alpha_{1}$ a higher $\alpha$ is associated with a higher $s^{s i}$, as shown in Lemma 1 and illustrated in Figure 4.

Case 2c. For $\alpha>\alpha_{2}$ IC and PC are binding, while F is not. Graphically, this occurs if the IC and PC curves intersect each other below the F curve and the intersection occurs in the increasing portion of the PC curve (as in Figure 3 ). This intersection, which identifies the optimal standard $s i$, is unique because the PC curve is concave and the IC curve is convex in $s$. Hence, for $\alpha>\alpha_{2}$ a higher $\alpha$ is associated with a lower $s^{s i}$, as shown in Lemma 1 and illustrated in Figure 3.

\section{Appendix B: Definitions and Sources of Variables}

Environmental Governance. Principal component of responses to several survey questions touching on air pollution regulation, chemical waste regulation, clarity and stability of regulations, flexibility of regulations, environmental regulatory innovation, leadership in environmental policy, stringency of environmental regulations, consistency of regulation enforcement, regulatory stringency, toxic waste disposal regulations, and water pollution regulations. This variable is available for 70 countries. Source: Porter, Sachs, and Schwab (2001) as reported in World Economic Forum (2002).

Compliance with Environmental Agreements. Indicator obtained from survey reactions to the statement: "Compliance with international environmental agreements is a high priority." Survey responses range from 1 (strongly disagree) to 7. This variable is available for 56 countries. Source: Porter, Sachs, and Schwab (2001) as reported in World Economic Forum (2002).

Corruption. Misuse of public power for private benefits (e.g., bribing of public officials, kickbacks in public procurement or embezzlements of public funds), 
as of 1999. The index averages the corruption scores given by the following sources: (i) Freedom House Nations in Transit; (ii) Gallup International; (iii) The Economist Intelligence Unit; (iv) the Institute for Management Development, Lausanne; (v) the International Crime Victim Survey; (vi) the Political and Economic Risk Consultancy, Hong Kong; (vii) the Wall Street Journal, Central European Economic Review, (viii) the World Bank and University of Basel; (ix) the World Economic Forum. The original index is the "corruption perception index" produced by Transparency International and is a descending score from 1 (most corrupt) to 10 (least corrupt). We rescale it so that our "corruption" variable equals 1 for the least and 10 for the most corrupt countries. In 1999 this variable is available for 92 countries. Source: 〈http://transparency.org〉.

Income. GDP per capita, constant prices (1995), average of 1994-1998. Available for 117 countries. Source: Penn World Table 6.0 (PWT 6.0).

Religion. Measures of the religious composition of the population that identify for the year 1980 the percentage of the population that is (i) Roman Catholic, (ii) Protestant, and (iii) Muslim, available for 85 countries. Source: La Porta et al. (1998) using data from World Christian Encyclopedia 1982, Worldmark Encyclopedia of Nations 1995, Statistical Abstract of the World 1995, Demographic Yearbook 1995, CIA World Factbook 1996.

Schooling. Average years of schooling in the total population over age 25 in 1980, as described by Barro and Lee (1993). Available for 77 countries. Source: 〈http://www.nber.org/pub/barro.lee〉.

Latitude. The absolute value of the latitude of the country, scaled to take values between 0 and 1. Available for 85 countries. Source: La Porta et al. (1998) using data from CIA Factbook.

Civil Rights. Index of civil liberties, average for the 1980s, Scale from 1 (most freedom) to 7 (least freedom). Available for 81 countries. Source: 〈http://www. nber.org/pub/barro.lee $)$.

\section{References}

Acemoglu, Daron, and Thierry Verdier (2000). "The Choice Between Market Failures and Corruption.” American Economic Review, 90, 194-211.

Banerjee, Abhijit V. (1997). “A Theory of Misgovernance.” Quarterly Journal of Economics, 112, 1289-1332.

Barro, Robert, and Jong Wah Lee (1993). "International Comparisons of Educational Attainment." Journal of Monetary Economics, 32, 363-394. 
Becker, Gary S. (1968). “Crime and Punishment: An Economic Approach.” Journal of Political Economy, 76, 169-217.

Becker, Gary S., and George J. Stigler (1974). "Law Enforcement, Malfeasance and Compensation of Enforcers." Journal of Legal Studies, 17, 65-81.

Bertrand, Marianne, Simeon Djankov, Hanna Rema, and Sendhil Mullainathan (2007). "Obtaining a Driver's License in India: An Experimental Approach to Studying Corruption." Quarterly Journal of Economics, 122, 1639-1676.

Botero, Juan, Simeon Djankov, Rafael La Porta, Florencio Lopez-de-Silanes, and Andrei Shleifer (2004). "The Regulation of Labor." Quarterly Journal of Economics, 119, 1339-1382.

Dasgupta, Susmita, Benoit Laplante, Hua Wang, and David Wheeler (2002). "Confronting the Environmental Kuznets Curve.” Journal of Economic Perspectives, 16, 147-168.

DeLong, J. Bradford, and Andrei Shleifer (1993). "Princes and Merchants: European City Growth before the Industrial Revolution." Journal of Law and Economics, 36, 671-702.

DeMarzo, Peter M., Michael Fishman, and Kathleen M. Hagerty (2005). "Contracting and Enforcement with a Self-regulatory Organization." Review of Economic Studies, 72, 687 706.

Djankov, Simeon, Rafael La Porta, Florencio Lopez-de-Silanes, and Andrei Shleifer (2002). "The Regulation of Entry." Quarterly Journal of Economics, 117, 1-37.

Djankov, Simeon, Rafael La Porta, Florencio Lopez-de-Silanes, and Andrei Shleifer (2003). "Courts." Quarterly Journal of Economics, 118, 453-517.

Glaeser, Edward L., and Andrei Shleifer (2003). "The Rise of the Regulatory State." Journal of Economic Literature, 41, 401-425.

Holmes, Stephen, and Cass R. Sunstein (1999). The Cost of Rights: Why Liberty Depends on Taxes. W. W. Norton \& Company.

Krueger, Anne (1974). "The Political Economy of the Rent-Seeking Society." American Economic Review, 64, 291-303.

Laffont, Jean Jacques, and Jean Tirole (1993). A Theory of Incentives in Procurement and Regulation. MIT Press.

La Porta, Rafael, Florencio Lopez-de-Silanes, Andrei Shleifer, and Robert W. Vishny (1998). "Law and Finance." Journal of Political Economy, 106, 1113-1155.

Malik, Arun S. (1990). "Avoidance, Screening and Optimum Enforcement." Rand Journal of Economics, 21, 341-353.

McChesney, Fred (1987). "Rent Extraction and Rent Creation in the Economic Theory of Regulation." Journal of Legal Studies, 16, 101-118.

Polinsky, Mitchell A., and Steven M. Shavell (2000). "The Economic Theory of Public Enforcement of Law." Journal of Economic Literature, 38, 45-76.

Polinsky, Mitchell A., and Steven M. Shavell (2001). "Corruption and Optimal Law Enforcement." Journal of Public Economics, 81, 1-24.

Porter, Michael E., Jeffrey Sachs, and Klaus Schwab, eds. (2001). The Global Competitiveness Report 2001-2002. World Economic Forum, Oxford University Press.

Rose-Ackerman, Susan (1978). Corruption: A Study in Political Economy. Academic Press.

Shavell, Steven (1991). "Specific versus General Enforcement of Law." Journal of Political Economy, 99, 1088-1108.

Shavell, Steven (1993). "The Optimal Structure of Law Enforcement." Journal of Law and Economics, 36, Part 2, 255-287.

Stigler, George J. (1970). “The Optimum Enforcement of Laws.” Journal of Political Economy, $78,526-536$.

Wade, Robert (1982). "The System of Administrative and Political Corruption: Canal Irrigation in South India." Journal of Development Studies, 18, 287-328.

World Economic Forum (2002). 2002 Environmental Sustainability Index Report. $\langle$ http://sedac.ciesin.columbia.edu/es/epi//. 